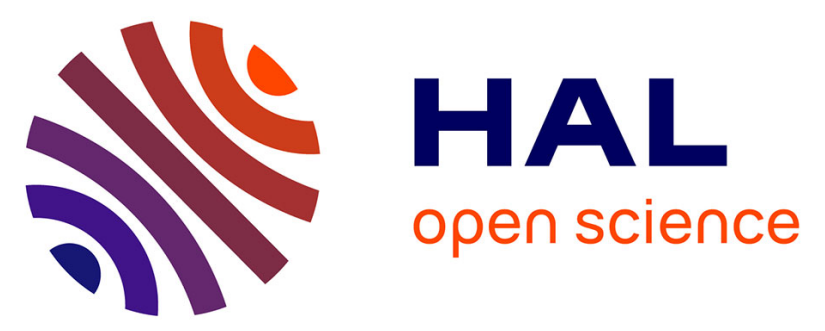

\title{
Ab Initio Semi-Quantitative Analysis of Micro-Beam Grazing-Incidence Small-Angle X-Ray Scattering (M-GISAXS) during Protein Crystal Nucleation and Growth
}

Claudio Nicolini, Nicola Luigi Bragazzi, Eugenia Pechkova, Rémi Lazzari

\section{To cite this version:}

Claudio Nicolini, Nicola Luigi Bragazzi, Eugenia Pechkova, Rémi Lazzari. Ab Initio Semi-Quantitative Analysis of Micro-Beam Grazing-Incidence Small-Angle X-Ray Scattering ( $M$-GISAXS) during Protein Crystal Nucleation and Growth. Journal of Proteomics and Bioinformatics, 2014, 07 (02), pp.064070. 10.4172/jpb.1000303 . hal-01243090

\author{
HAL Id: hal-01243090 \\ https://hal.science/hal-01243090
}

Submitted on 14 Dec 2015

HAL is a multi-disciplinary open access archive for the deposit and dissemination of scientific research documents, whether they are published or not. The documents may come from teaching and research institutions in France or abroad, or from public or private research centers.
L'archive ouverte pluridisciplinaire HAL, est destinée au dépôt et à la diffusion de documents scientifiques de niveau recherche, publiés ou non, émanant des établissements d'enseignement et de recherche français ou étrangers, des laboratoires publics ou privés. 


\title{
Ab Initio Semi-Quantitative Analysis of Micro-Beam Grazing-Incidence Small-Angle X-Ray Scattering (M-GISAXS) during Protein Crystal Nucleation and Growth
}

\author{
Claudio Nicolini ${ }^{1,2,3,4 *}$, Nicola Luigi Bragazzi ${ }^{1,2}$, Eugenia Pechkova ${ }^{1,2}$ and Rémi Lazzari ${ }^{3}$
}

${ }^{1}$ Biophysics and Nanobiotechnology Laboratories (BNL), Department of Experimental Medicine (DIMES), University of Genoa, Via Antonio Pastore 3, Genoa 16132, Italy ${ }^{2}$ Nanoworld Institute Fondazione El.B.A. Nicolini (FEN), Largo Redaelli 7, Pradalunga, Bergamo 24100, Italy

${ }^{3}$ Sorbonne Universités, UPMC Univ Paris 06, UMR 7588, Institut des NanoSciences de Paris, 75005 Paris, France and CNRS, UMR 7588, Institut des NanoSciences de Paris, 75005 Paris, France

${ }^{4}$ European Synchrotron Radiation Facility (ESRF), 6 Rue Jules Horowitz, 38000 Grenoble, France

\begin{abstract}
Micro-beam Grazing-Incidence Small-Angle X-ray scattering ( $\mu$-GISAXS), exploiting both the advantages of elastic X-ray scattering and the highly focused third-generation synchrotron radiation micro-beams, is an advanced scattering technique that enables scientists to unravel the details of crystal growth processes and to investigate large-scale structures in thin films, including nanobiofilms or other different kinds of surfaces, such as surface gradients or confined surfaces.

In this study, we analyze semi-quantitatively and we simulate our previously acquired $\mu$-GISAXS experiments of Thaumatin and Lysozyme Langmuir-Blodgett (LB)-film, shedding light on nucleation and crystal growth processes. Here, we show that, during LB-thin film facilitated nucleation, the particle radius of Thaumatin and of Lysozyme crystal increases while the film thickness reduces. Structural re-organization inside and within the LB-thin film are likely to lead to the crystal nucleation and growth. These semi-quantitative findings are in agreement with the model previously hypothesized. New insights and implications for protein nanocrystallography are also discussed.
\end{abstract}

Keywords: $A b$ initio semi-quantitative analysis; Crystal growth; Crystal nucleation; IgGISAXS; Langmuir-Blodgett (LB) nanobiotemplate; Lysozyme; Micro-beam Grazing-Incidence SmallAngle X-ray Scattering-( $\mu$-GISAXS); Thaumatin

\section{Introduction}

Protein crystallization is a challenging issue for solving and determining the crystallographic structures of molecules of crucial medical importance: it is a time-consuming, highly demanding task, characterized by many rate-limiting steps and bottlenecks [1-5].

Problems and difficulties due to the identification of the precise crystallization conditions and parameters [6] are often encountered in classical crystallography, despite its advancements and achievements [7].

In order to overcome these issues, in the last years we developed and proposed an approach termed as "protein nanocrystallography" or better "protein nanobiocrystallography", in which nanobiotechnologies play a major role. Protein crystal nucleation and growth are facilitated and enhanced through a Langmuir-Blodgett (LB)-based nanobiotemplate [8-14].

LB nanobiotemplate enables scientists to finely manipulate molecules and proteins, and allows the development and design of highly ordered nanobiopatterns and sensitive nanobiosensors [15-17].

In many investigations, we found that protein crystals grown on nanobiotemplate surfaces exhibit very interesting features, such as thermostability $[18,19]$, enhanced radiation resistance [20-22], unique water structure [23,24] and submicron domains [25].

The growth of protein (such as, for example, Cytochrome P450scc, Thaumatin and Lysozyme) films on homologous crystal surfaces has been studied and characterized by Atomic Force Microscopy (AFM) [26-28], but microscopic details of the crystal growth process are still poorly known.
Grazing-incidence Small Angle X-ray scattering (GISAXS) is an advanced scattering technique that can be used to unravel these processes and to investigate large-scale structures in thin films, including biofilms [29,30].

A combination of this technique with third-generation synchrotron radiation micro-beams ( $\mu$-GISAXS) [31] has been used for studying different kinds of surfaces, like surface gradients or confined surfaces. The potential for studying thin protein films by $\mu$-GISAXS during nanotemplate-assisted crystallization experiments was previously demonstrated in a study about the effect of temperature on long-range order [19] and during both ex situ and in situ experiments [32-36]. Ex situ data obtained using both Cytochrome P450scc and Lysozyme were extremely complex to interpret and needed to be studied in parallel with microscopy characterization, using either the classical method or the nanotemplate hanging-drop method [32,33], as well as in situ data [34-36].

Moreover, ex situ experiments were partially limited by the

*Corresponding author: Claudio Nicolini, Biophysics and Nanobiotechnology Laboratories (BNL), Department of Experimental Medicine (DIMES), University of Genoa, Via Antonio Pastore 3, Genoa 16132, Italy, Tel: +39 010353 38217; E-mail: clannicolini@gmail.com

Received November 01, 2013; Accepted February 18, 2014; Published February 21, 2014

Citation: Nicolini C, Bragazzi NL, Pechkova E, Lazzari R (2014) Ab Initio SemiQuantitative Analysis of Micro-Beam Grazing-Incidence Small-Angle X-Ray Scattering (M-GISAXS) during Protein Crystal Nucleation and Growth. J Proteomics Bioinform 7: 064-070. doi:10.4172/jpb.1000303

Copyright: (C) 2014 Nicolini C, et al. This is an open-access article distributed under the terms of the Creative Commons Attribution License, which permits unrestricted use, distribution, and reproduction in any medium, provided the original author and source are credited. 
discontinuous nature of the studies themselves and for addressing this issue, in situ experiments were carried out, designing an ad hoc apparatus, namely the flow-through crystallization cell, which, besides the conventional crystallization set-up, is made up by two kapton windows being inserted into the outer cell walls (Figure 1) [35,37]. For obtaining a rapid and proper buffer exchange, the reservoir was connected via Teflon tubes to two Harvard syringe pumps. The main advantage of in situ experiments was the possibility of monitoring the different processes of crystal growth in real time.

The aim of this work is to shed light on the processes of nucleation and crystal growth starting from a LB-protein film by semi-quantitatively analyzing previously acquired in situ $\mu$-GISAXS experiments with suitable models [34-36].

We want to stress and underline some limitations of our simulation analysis. The used model of cylinder is only a starting point of the analysis to grasp the main evolution of the morphology of the surface i.e. crystallites on a LB thin film. However, the process of protein crystallization and the corresponding morphology may be much more complex than this approximate picture of the surface roughness. This explains the difficulties of finding simultaneously the right power law decrease of the intensity along the two directions of space. On the other hand, even if preliminary, this work represents advancement in comparison with the only qualitative analysis we previously carried out.

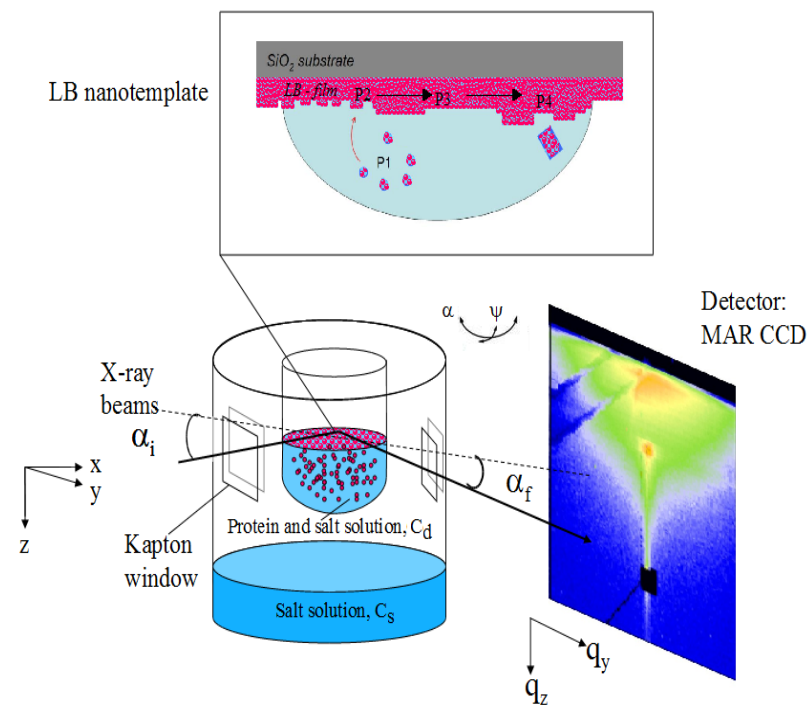

Figure 1: Schematic view of the experimental lay-out for in situ $\mu$-GISAXS simulation of protein crystallization by Langmuir-Blodgett (LB) nanotemplate method. The experimental set-up has been mounted at ID13 beam-line at ESRF as described more in details in Gebhardt et al. [34-36]. The vapor deposition cylinder contains two stainless Kapton windows (transparent to the X-rays) and the Lysozyme/Thaumatin solution typical droplet hanging on the Lysozyme/ Thaumatin two layers deposited over the glass. The cylinder is mounted on an xyz gantry and a two-axis goniometer $\left(\varphi_{x}, \varphi_{y}\right)$. The scan is made in the $y$ direction. $\alpha_{i}$ denotes the angle between the incident beam and the sample surface, $\alpha_{f}$ the corresponding exit angle, and $2 \varphi$ the out-of-plane angle. The flight path $(L=1.15 \mathrm{~m})$ between the sample and the two-dimensional detector is evacuated $\left(10^{-2} \mathrm{mbar}\right)$. On the right is shown the typical two-dimensional MGISAXS signal of the Lysozyme/Thaumatin drop sitting on a layer. Above, the working hypothesis (the model of the pathway association within the LB nanobiotemplate, leading to the crystal nucleation and growth) is shown.

\section{Materials and Methods}

\section{Thaumatin crystallization}

Thaumatin I, a plant sweet protein from Thaumatococcus daniellii (T7638, molecular mass $22 \mathrm{kDa}$ ) was purchased from Sigma Aldrich (Milan, Italy). Thaumatin protein monolayers were deposited onto glass slides by the Langmuir-Schaefer (LS) method, which enables to obtain a highly packed and ordered Thaumatin monolayer with a surface density of $\sim 9.69 \cdot 10^{10}$ molecules $/ \mathrm{mm}^{2}$, corresponding to $\sim 10.32 \mathrm{~nm}^{2} /$ molecule, which fits well with the molecule geometric features from the Protein Data Bank (PDB code 3DZR) and from AFM measurements of LS film $[35,36]$.

The $100 \mathrm{ml}$ of filtered (0.45-mm filter unit, Millipore, Carrigtwohill, Ireland) protein solution of concentration $1 \mathrm{mg} / \mathrm{ml}$ were spread onto the air-water interface of the Langmuir-Blodgett (LB) with a Hamilton syringe (Reno, NV).

Distilled water purified with a Milli-Q system $(18.2 \mathrm{M} \Omega \cdot \mathrm{cm}$; standard protocol ISO 3696; Millipore, Billerica, MA) was used as sub-phase. The protein monolayer was compressed immediately after spreading to a surface pressure of $20 \mathrm{mN} / \mathrm{m}$. Transfer of the protein monolayer from the sub-phase surface onto a solid support was performed by touching the support parallel to the sub-phase surface according to the LS technique (horizontal lift) at a fixed surface pressure. The crystallization conditions used for the modified hangingdrop method reported here, with two LB layers of Thaumatin, were as follows. A $4-\mathrm{ml}$ drop containing $15 \mathrm{mg} / \mathrm{ml}$ of Thaumatin in 100 $\mathrm{mM} \mathrm{N}$-(2-Acetamido)iminodiacetic Acid (ADA) buffer, at $\mathrm{pH}$ 6.5, was mixed with $4 \mathrm{ml}$ of the reservoir solution (1 M sodium/potassium tartrate in $100 \mathrm{mM}$ sodium/potassium tartrate buffer, at $\mathrm{pH} 6.5$ ) and placed on a siliconized glass slide in the classical method, or on a Thaumatin nanotemplate in the LB method, and stabilized over the reservoir containing $1 \mathrm{M}$ sodium/potassium tartrate in $100 \mathrm{mM}$ sodium/potassium tartrate buffer, $\mathrm{pH} 6.5$ [35,36].

\section{Lysozyme crystallization}

Lysozyme (EC 3.2.1.17, of Gallus gallus) was purchased from Sigma Aldrich (Milan, Italy). Lysozyme is a $15 \mathrm{kDa}$ protein of 129 amminoacids, that hydrolyzes different polysaccharides and has antibacterial properties. Lysozyme thin film was prepared on the water-area interface and compressed to a surface pressure of $25 \mathrm{mN} \mathrm{m}^{-1}$ by means of a LB trough. A protein monolayer was deposited onto a siliconized glass circle cover slide of $12 \mathrm{~mm}$ diameter (Hampton Research) by the LS method. This highly ordered protein nanotemplate was utilized in a hanging-drop protein crystallization method modification. The droplet of protein solution and the precipitant (salt) was placed on the glass slide covered by thin film nanotemplate. As in the classical hanging-drop method, the glass slide with the protein template and the drop was sealed on the crystallization plate (Limbro plate, Hampton Research) using vacuum grease. The crystallization conditions usually used for the classical hanging-drop method were applied: a $6 \mu$ drop containing $20 \mathrm{mg} / \mathrm{ml}$ Lysozyme in $50 \mathrm{mM}$ sodium acetate buffer at $\mathrm{pH}$ 4.5 and $0.45 \mathrm{M}$ sodium chloride was placed on the siliconized glass slide covered with the Lysozyme monolayer and stabilized over the reservoir containing $1.8 \mathrm{M}$ sodium chloride in sodium acetate buffer for the first 20 minutes (accelerated nucleation) and $0.9 \mathrm{M}$ up to the following 24 hours (controlled growth) [34].

\section{Experimental Thaumatin and Lysozyme $\mu$-GISAXS}

In situ scattering experiments were performed at the ID13 
microfocus beamline facility at the European Synchrotron Radiation Facility in Grenoble, France [34-36]. $\mu$-GISAXS is an advanced scattering method which allows investigating large-scale structures in thin film [38-40] but which requires brilliant and focused beam from a synchrotron source. The incoming monochromatic beam $(\lambda=0.991 \AA$ $-12.7 \mathrm{keV}$ ) was focused by a set of two crossed Fresnel lenses on a spot of dimensions $0.5 \times 1 \mu \mathrm{m}^{2}$ (full width at half-maximum) at the sample position with a flux of $\sim 10^{10}$ photons/s. A micro-ionisation chamber with a $20 \mu \mathrm{m}$ guard aperture was used to monitor beam intensity and to reduce parasitic scattering. The direct beam was blocked by a $300 \mu \mathrm{m}$ - diameter beam stop to avoid overexposure of the detector.

The flow-through crystallization cell (pictorially shown in Figure 1 ) was placed on a two-axis goniometer with rotating angle $(\alpha, \psi)$, mounted on an $x / y / z$ translation unit with the X-ray beam direction along the $x$-axis.

The crystallization cell set-up was tilted by the goniometer to adjust the fixed angle of incidence $\left(\alpha_{i}=0.71^{\circ}\right)$.

The $\mu$-GISAXS pattern was recorded on a MAR165 CCD detector $(2000 \times 2000$ pixels with a $78.94 \times 78.94$-mm pixel size; 16 -bit readout $)$. The sample-to-detector distance was $791 \mathrm{~mm}$ as determined by an Agbehenate standard [41].

A typical $\mu$-GISAXS pattern is indexed as function of the wavevector transfer $Q=\left(Q_{x}, Q_{y}, Q_{z}\right)$ which parallel $Q_{y}$ and perpendicular $\mathrm{Q}_{\mathrm{z}}$ components scale with the in-plane $2 \alpha_{i}$ and exit $\alpha_{\mathrm{f}}$ scattering angles [42]. Knowing $\alpha_{i}$ is the grazing incidence angle, $Q_{Y}$ and $Q_{Z}$ can be computed as follows:

$$
\begin{aligned}
& \mathrm{Q}_{\mathrm{Y}}=2 \pi / \lambda \sin \left(2 \alpha_{\mathrm{i}}\right) \cos \left(\alpha_{\mathrm{f}}\right) \\
& \mathrm{Q}_{\mathrm{Z}}=2 \pi / \lambda\left[\sin \left(\alpha_{\mathrm{f}}\right)+\sin \left(\alpha_{\mathrm{i}}\right)\right]
\end{aligned}
$$

While $\mathrm{Q}_{\mathrm{x}}$ is negligible in most conditions.

The specular and the so called Yoneda Peak [43] occur as characteristic features in the scattering patter.

Real GISAXS patterns are shown in Figures 2 and 3 for Thaumatin and for Lysozyme, respectively.

A typical $\mu$-GISAXS pattern of Thaumatin is shown in Figure 4 [35,36]. Specular scattering is observed for $Q_{x}=Q_{y}=0, Q_{z}>0$, with the specular peak appearing when the specular condition is fulfilled $\left(\alpha_{i}\right.$ $=a_{f}$ ), and while diffuse scattering is observed for $Q_{z} Q_{y} \neq 0$. The so called Yoneda Peak $\alpha_{c}=\alpha_{f}$ occurs at the critical angle $\alpha_{c}$ of the sample. Correlations vertical to the sample surface can be probed along $Q_{z}$ at $\mathrm{Q}_{\mathrm{y}}=0[43]$.

For the LB-Lysozyme $\mu$-GISAXS, which is shown in Figure 5, was acquired for 1 second at a time interval of 2 minutes in the first 30 minutes, while at $t=26$ minutes the acquisition time was changed to 5 seconds [34]. Images were recorded up to a total of 93 . For the classical Lysozyme, $\mu$-GISAXS was acquired for $5+5$ seconds at a time interval of 110 seconds from 30 minutes up to 3 hours; a total of 268 images were recorded.

The excluded area in Figure 5 takes into account only the sharp peak due to the reflected beam. The bump may arise from the interplay between the foot of the sharp peak and the surface roughness, which is difficult to model. But, as we previously stated and emphasized, the used model of cylinder is only semi-quantitative and reproduces only the overall power law decay of the intensity.
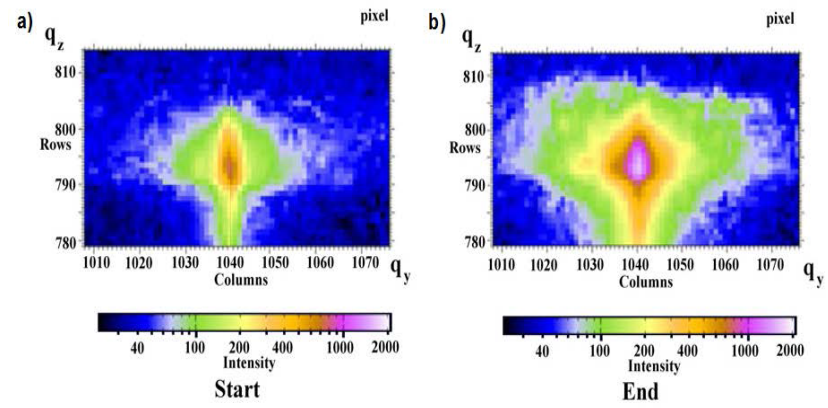

Figure 2: Real Yoneda peak region within the real GISAXS pattern of growing Thaumatin crystals in the presence of LB nanotemplate at the beginning (left) and the end (right) of data acquisition. $Q_{z}$ increases from the top to the bottom of the graphs toward a decreasing row numbers of pixels on the detector, and $Q_{y}$, given as columns, increases to the left and right from the center of the pattern (slightly modified from $[35,36]$ ).
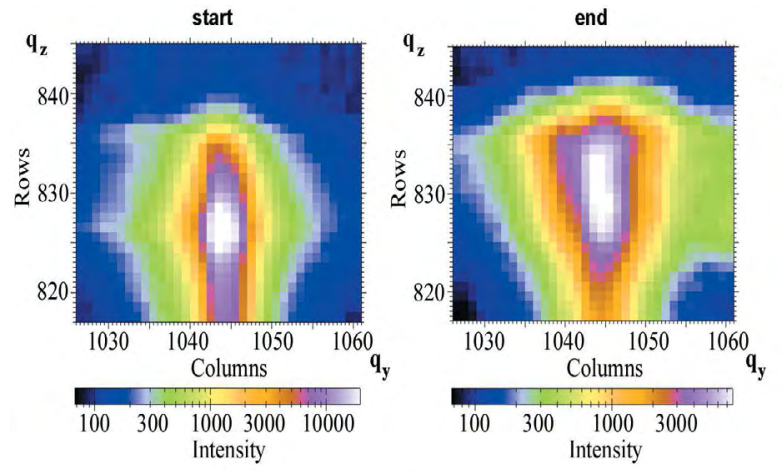

A

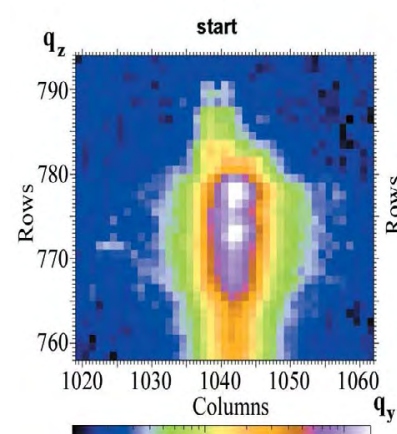

$20 \quad 40 \quad 100200400 \quad 1000$ Intensity

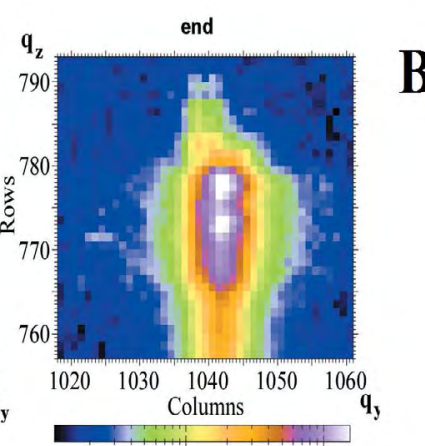

$20 \quad 40 \quad 100200400 \quad 1000$
Figure 3: Yoneda regions of the lysozyme nanotemplate-based drop (A) and the classical one (B). The patterns are shown on a logarithmic scale to enhance the features in the Yoneda regions (slightly modified from [34]).

Characteristic morphological parameters of the sample, such as shape and distances, can be extracted from analysis of out-of-plan scans along the $\mathrm{Q}_{\mathrm{z}}$ direction, as discussed in detail elsewhere $[35,36]$.

Critical angles of Thaumatin, Lysozyme and glass for the used $\mathrm{X}$-ray energy were calculated on the basis of their chemical formula and densities [44].

\section{Data reduction}

The Fit2D software package was used for data reduction [45]. GISAXS patterns were analyzed with the IsGISAXS software [46- 

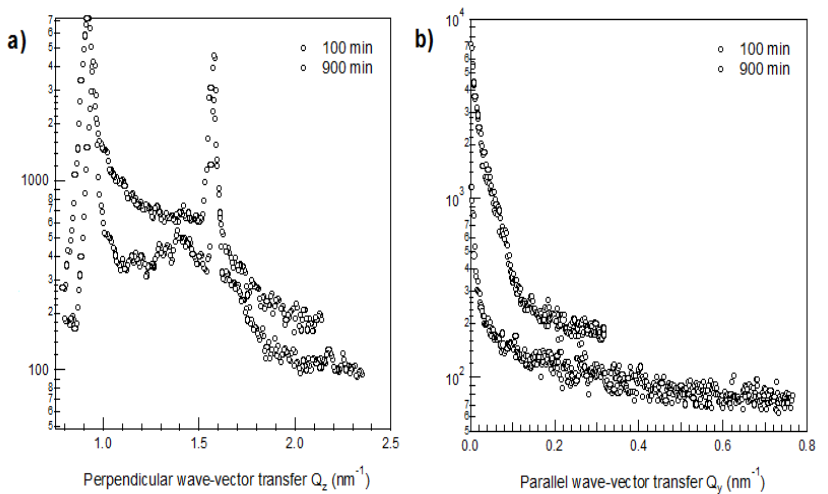

Figure 4: Thaumatin - Experimental curves with LB.

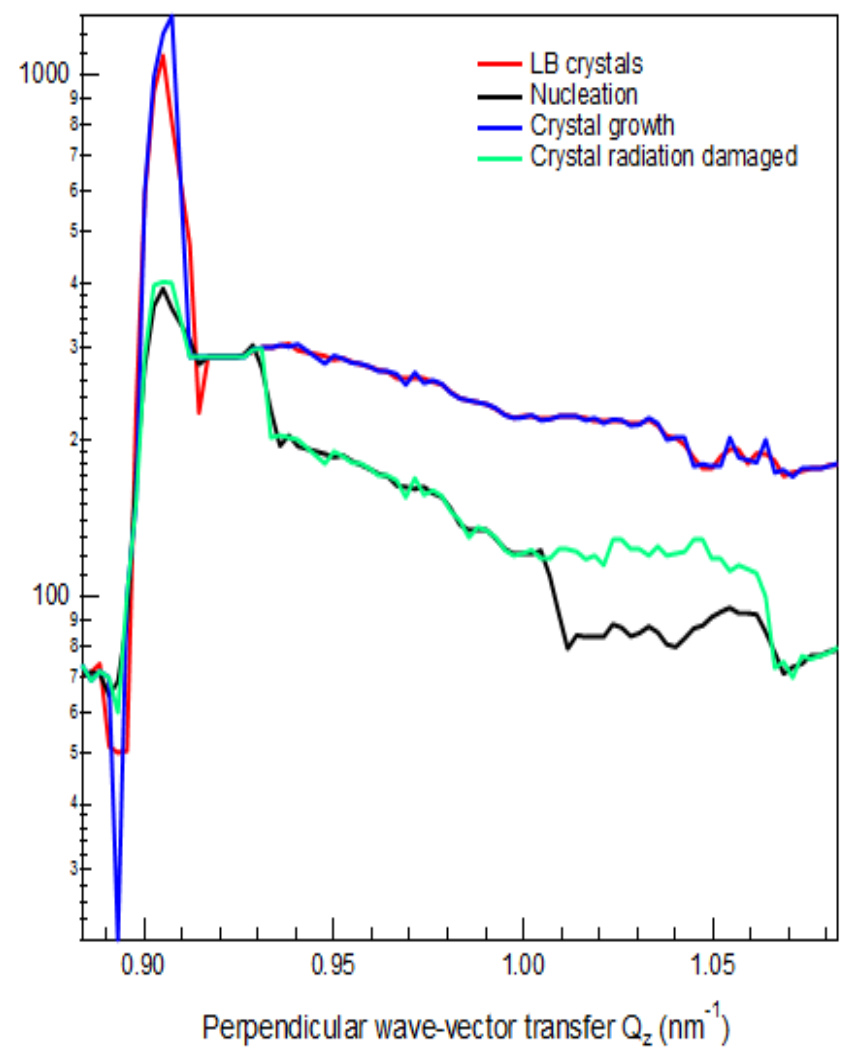

Figure 5: Lysozyme - Experimental curves with and without LB.

50] which is dedicated to simulation of scattering from supported nanostructures. The scattering cross section is expressed in terms of island form factor and interference function and the specificity of the grazing-incidence geometry is stressed, in particular in the evaluation of the island form factor in the distorted-wave Born approximation (DWBA). A full account of size and possible shape distributions is given in the decoupling approximation (DA), where sizes and positions are not correlated, and in the local mono-disperse approximation (LMA). Two types of island repartitions on the substrate can be implemented: disordered systems characterized by their particle-particle pair correlation functions, and bi-dimensional crystalline or paracrystalline systems of particles.

\section{Choice of parameters}

The scheme adopted for ab initio data reduction is shown pictorially in Figure 1 and described in details in Gebhardt et al. [35,36].

In table 1, the parameters which have been used in our simulation for modeling the crystal growth have been reported. Proteins have been modeled as cylinders, LB film thickness, found with the best fit, was fixed at $7.4 \mathrm{~nm}$ for Thaumatin and at $6.4 \mathrm{~nm}$ for Lysozyme, while the wavelength was experimentally known $(0.0991 \mathrm{~nm})$. Critical incident angle for Thaumatin and for Lysozyme was computed to be $0.71 \mathrm{deg}$. The delta refraction coefficients were $3.336 \cdot 10^{-6}$ for glass, $2.19 \cdot 10^{-6}$ for proteins. The beta absorption coefficients were about 0 for proteins, $1.68 \cdot 10^{-8}$ for glass.

Curves have been fitted with a $\chi^{2}$ Levenberg-Marquardt minimization procedure, which is an iterative technique commonly used for solving non linear least squares problems, with constant standard error bars of $\sigma R / R=0.005$ by means of the IsGISAXS software.

\section{Results and Discussion}

Combination of GISAXS, synchrotron microfocus beam and computer simulation has enabled us to follow the nucleation and growth of the Lysozyme and the Thaumatin crystals.

The real GISAXS patterns are shown in Figures 2 and 3 for Thaumatin and Lysozyme, respectively.

The experimental curves of LB Thaumatin, which have been used for the fitting and simulations, are shown in Figure 4.

At 100 minutes, the particle radius of Thaumatin is about $5.62 \mathrm{~nm}$, while the LB-film layer thickness is about $2.25 \mathrm{~nm}$, with height ratio of $1 \mathrm{~nm}$ (Figure 6, where is shown the perpendicular cut along $\mathrm{Q}_{\mathrm{Z}}$ ). For Figure 6, the same remarks and observations concerning Figure 5 about the excluded area are valid.

At 900 minutes from the start of the experiment, the particle radius has increased up to $40.89 \mathrm{~nm}$, while on the contrary the LB-film layer thickness has decreased down to $0 \mathrm{~nm}$, with a decreased height ratio of $6.30 \cdot 10^{-2} \mathrm{~nm}$. In Figure 7 the cut at Q parallel is shown at right, while at left of the same Figure 7 the cut at Q perpendicular is shown.

Previously, we hypothesized that the protein appears to transfer directly from the nano-biostructured film into the drop to directly trigger the formation of the crystal, therefore highlighting the physical interpretation of the mechanism for nanobiotemplate-facilitated protein crystallization [35,36]. This working hypothesis however was only qualitative and not quantitative, since the GISAXS spectra were

\begin{tabular}{|l|c|}
\hline Modeling Parameters & Value \\
\hline Wavelength (nm) & 0.0991 \\
\hline Incident angle (deg) & 0.71 \\
\hline Delta - Glass (index of refraction) & $3.336 \mathrm{e}-6$ \\
\hline Delta - Thaumatin (index of refraction) & $2.19 \mathrm{e}-6$ \\
\hline Delta- Lysozyme (index refraction) & $1.68 \mathrm{e}-8$ \\
\hline Beta - Glass (absorption) & $\sim 0$ \\
\hline Beta - Protein (absorption) & 7.4 \\
\hline LB 2 Layers thickness Thaumatin (nm) & 6.4 \\
\hline LB 2 Layers thickness Lysozyme (nm) & \\
\hline
\end{tabular}

Table 1: Modeling parameters used for the computer simulations. 


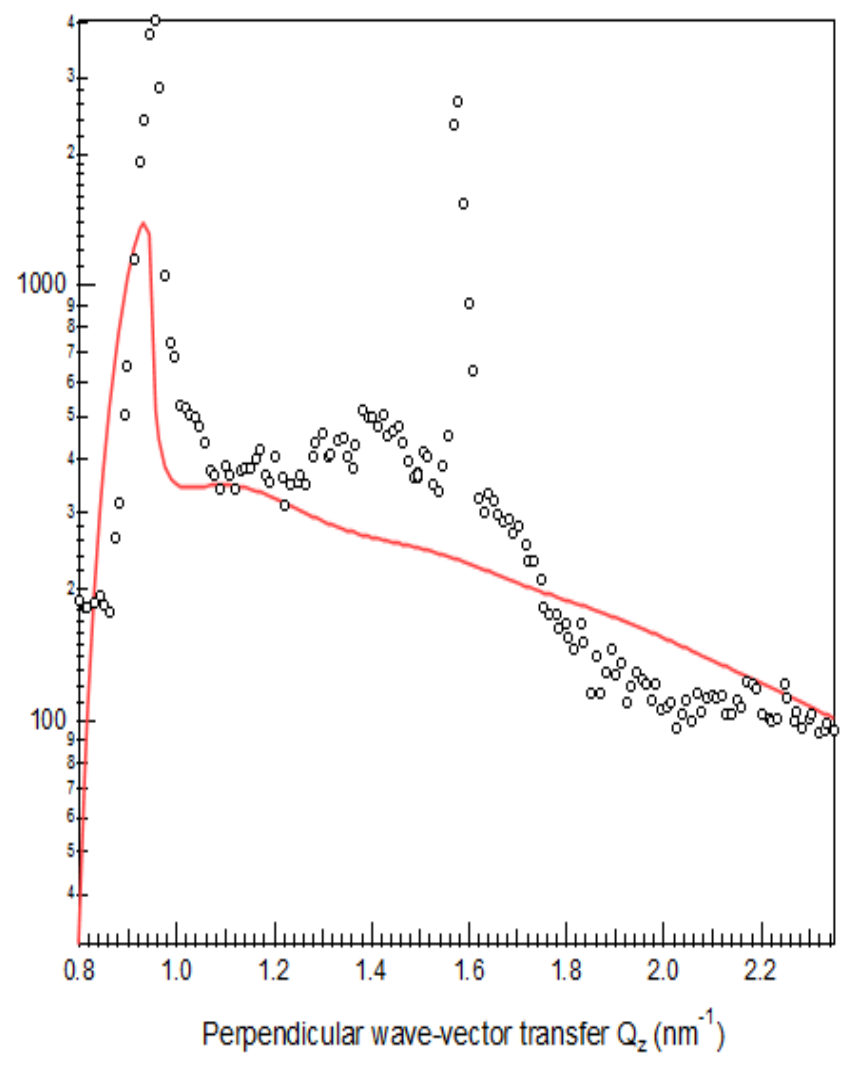

Figure 6: Thaumatin $-100 \mathrm{~min}-$ Modeling crystal growth. Cylinder: Size $=$ Fixed - Height $=1.7 \mathrm{~nm}-$ Fixed LB thickness $=7.4 \mathrm{~nm}$.
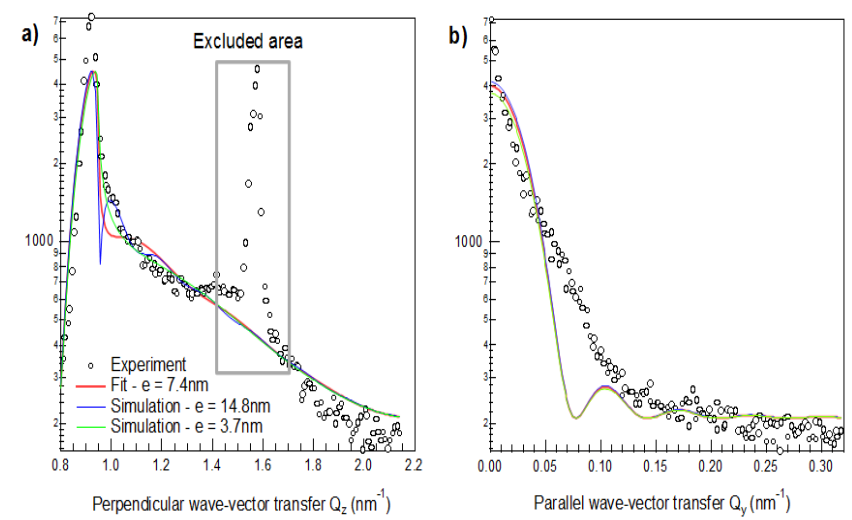

Figure 7: Thaumatin -900min - Modeling crystal growth. Cylinder: Size $=95$ $\mathrm{nm}-$ Height $=5.6 \mathrm{~nm}-$ Fixed LB thickness $=7.4 \mathrm{~nm}$. Blue line $=$ Simulation with fixed LB thickness $=14.8$ and $3.7 \mathrm{~nm}$. Perpendicular wave-vector transfer $\mathrm{Q}_{Z}\left(\mathrm{~nm}^{-1}\right)$ (left), parallel wave-vector transfer $\mathrm{Q}_{\mathrm{Y}}\left(\mathrm{nm}^{-1}\right)$ (right).

complex and difficult to interpret. Indeed only computer simulation can help us in understanding the biological processes at sub-micron and nano-scale level, thus shedding light on protein nanocrystallography and paving the way for further research in the field.

For Lysozyme, a comparison between with and without LB-thin film was indeed possible in a different way, because the acquired data [34] were quite less optimal than the Thaumatin one $[35,36]$ due to a poor alignment [34]. The experimental curves are shown in Figure 5, where at $\mathrm{Q}$ perpendicular cut the difference between the intensity of the scattering of the LB Lysozyme, reaching its optimal growth, and the intensity of the classical structure, suffering more from radiation damage, is strikingly visible. The process of crystal growth previously found for Thaumatin was found also for Lysozyme: in Figure 8, the Gaussian fit of the Yoneda peak region of LB-Lysozyme monitored at start and at end of the crystallization process, showing the gradual increase in $\mathrm{R}$ (which is the ratio of crystal protein scattering volume to glass scattering volume elevated to the square). At $\mathrm{Q}$ perpendicular cut, $\mathrm{R}$ is 0.27 at the beginning (Figure 8, left) and gradually shifts to 1.13 (Figure 8, right).

Taken together the data of Lysozyme and of Thaumatin, we have proved that LB-thin film acts a transferring nanobiotemplate and can really enhance and facilitate crystallization growth, which is often difficult and demanding.

Moreover, the semi-quantitative findings we obtained are in perfect agreement with the model hypothesized in Gebhardt et al. [35,36].

\section{Conclusion}

The models here introduced are based on the submicron GISAX experiments being previously carried out at the ID13 beamline at ESRF on Thaumatin [35,36] and Lysozyme [34] and point to an highly unstable time dependent growth for Lysozyme crystals contrary to what is happening for Thaumatin growth. In addition the lysozyme experimentation appear compatible with a model where the LB crystals keep growing at a constant rate while the classic crystals interrupt their growth in the same time interval.

LB-grown proteins show peculiar and unique features at the submicron size [51]. LB-assisted crystal growth was previously studied by means of AFM, ex situ and in situ $\mu$-GISAXS [52,53] but obtained data were complex and difficult to reduce. IsGIXAS has enabled to model the crystal growth, even though with the limitations and the difficulties we underlined in the introduction section.

Our previously hypothesized model of LB-based crystal growth $[35,36]$ was here confirmed from a semi-quantitative point of view. a)

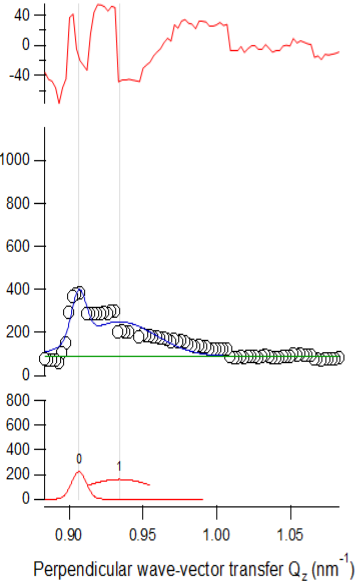

b)

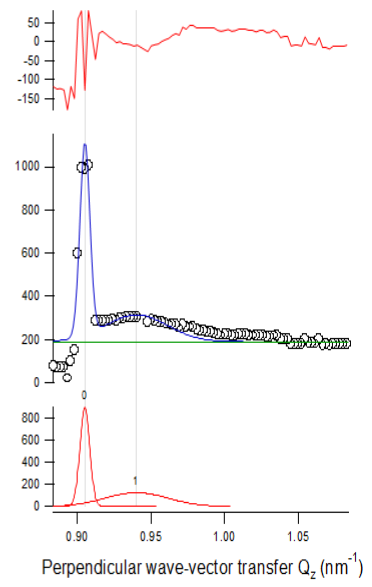

Figure 8: Gaussian fit of Yoneda peak region of LB-Lysozyme at the start (left) and at the end (right) of the crystallization process. $\mathrm{R}$ is the ratio of crystal protein scattering volume to glass scattering volume to the square. 
Citation: Nicolini C, Bragazzi NL, Pechkova E, Lazzari R (2014) Ab Initio Semi-Quantitative Analysis of Micro-Beam Grazing-Incidence Small-Angle X-Ray Scattering (M-GISAXS) during Protein Crystal Nucleation and Growth. J Proteomics Bioinform 7: 064-070. doi:10.4172/jpb.1000303

\section{Acknowledgements}

This work was supported by FIRB Nanobiosensors (ITALNANONET RBPR05JH2P 003) of MIUR (Ministero dell'Istruzione, Università e Ricerca) to Professor Dr. Claudio Nicolini University of Genoa, and by a grant Funzionamento by MIUR (Ministero dell'Istruzione, Università e Ricerca) to Fondazione El.B.A.Nicolini (FEN).

We thank ESRF for cooperation and precious support.

Dr. Nicola Luigi Bragazzi is from $5^{\text {th }}$ July 2012 also Resident in Public Health at the School of Public Health, Department of Health Sciences (DISSAL), University of Genoa, Via Antonio Pastore 1, Genoa 16132 (Italy).

\section{References}

1. Hol WGJ, Verlinde CLMJ (2006) Macromolecular crystallography and medicine. In International Tables for Crystallography.

2. Nicolini C, Pechkova E (2010) An overview of nanotechnology-based functional proteomics for cancer and cell cycle progression. Anticancer Res 30: 20732080.

3. Nicolini C, Pechkova E (2010) Nanoproteomics for nanomedicine. Nanomedicine (Lond) 5: 677-682.

4. Nicolini C, Bezerra T, Pechkova E (2012) Protein nanotechnology for the new design and development of biocrystals and biosensors. Nanomedicine (Lond) 7: $1117-1120$.

5. Nicolini C, Bragazzi N, Pechkova E (2012) Nanoproteomics enabling personalized nanomedicine. Adv Drug Deliv Rev 64: 1522-1531.

6. Bodenstaff ER, Hoedemaeker FJ, Kuil ME, de Vrind HP, Abrahams JP (2002) The prospects of protein nanocrystallography. Acta Crystallogr D Biol Crystallogr 58: 1901-1906.

7. Moraes I, Evans G, Sanchez-Weatherby J, Newstead S, Stewart PD (2014) Membrane protein structure determination - the next generation. Biochim Biophys Acta 1838: 78-87.

8. Nicolini C, Pechkova E (2004) Nanocrystallography: an emerging technology for structural proteomics. Expert Rev Proteomics 1: 253-256.

9. Nicolini C, Pechkova E (2006) Nanostructured biofilms and biocrystals. J Nanosci Nanotechnol 6: 2209-2236.

10. Pechkova E, Nicolini C (2002) Protein nucleation and crystallization by homologous protein thin film template. J Cell Biochem 85: 243-251.

11. Pechkova E, Fiordoro S, Fontani D, Nicolini C (2005) Investigating crystalgrowth mechanisms with and without LB template: protein transfer from LB to crystal. Acta Crystallogr D Biol Crystallogr 61: 809-812.

12. Pechkova, E, Nicolini C (2003) Proteomics and Nanocrystallography. Kluwer Academic Press, The Netherlands.

13. Pechkova E, Nicolini C (2004) Protein nanocrystallography: a new approach to structural proteomics. Trends Biotechnol 22: 117-122.

14. Pechkova E, Vasile F, Spera R, Fiordoro S, Nicolini C (2005) Protein nanocrystallography: growth mechanism and atomic structure of crystals induced by nanotemplates. J Synchrotron Radiat 12: 772-778.

15. Nicolini C, Bruzzese D, Cambria MT, Bragazzi NL, Pechkova E (2013) Recombinant laccase: I. Enzyme cloning and characterization. J Cell Biochem 114: 599-605.

16. Bragazzi NL, Pechkova E, Scudieri D, Terencio TB, Adami M, et al. (2012) Recombinant laccase: II. Medical biosensor. Crit Rev Eukaryot Gene Expr 22: 197-203.

17. Nicolini C, Adami M, Sartore M, Bragazzi NL, Bavastrello V, et al. (2012) Prototypes of newly conceived inorganic and biological sensors for health and environmental applications. Sensors (Basel) 12: 17112-17127.

18. Pechkova E, Innocenzi P, Malfatti L, Kidchob T, Gaspa L, et al. (2007) Thermal stability of lysozyme Langmuir-Schaefer films by FTIR spectroscopy. Langmuir 23: $1147-1151$

19. Pechkova E, Tripathi S, Nicolini C (2009) MicroGISAXS of Langmuir-Blodget protein films: effect of temperature on long-range order. J Synchrotron Radiat 16: $330-335$

20. Pechkova E, Tripathi S, Ravelli RB, McSweeney S, Nicolini C (2009) Radiation stability of proteinase $\mathrm{K}$ crystals grown by LB nanotemplate method. J Struct Biol 168: 409-418.
21. Pechkova E, Tropiano G, Riekel C, Nicolini C (2004) Radiation stability of protein crystals grown by nanostructured templates: synchrotron microfocus analysis. Spectrochim. Acta B At Spectrosc 59: 1687-1693.

22. Belmonte L, Pechkova E, Tripathi S, Scudieri D, Nicolini C (2012) LangmuirBlodgett nanotemplate and radiation resistance in protein crystals: state of the art. Crit Rev Eukaryot Gene Expr 22: 219-232.

23. Pechkova E, Sivozhelezov V, Nicolini C (2007) Protein thermal stability: the role of protein structure and aqueous environment. Arch Biochem Biophys 466 $40-48$.

24. Pechkova E, Sivozhelezov V, Belmonte L, Nicolini C (2012) Unique water distribution of Langmuir-Blodgett versus classical crystals. J Struct Biol 180: 57-64.

25. Pechkova E, Nicolini C (2010) Domain organization and properties of LB lysozyme crystals down to submicron size. Anticancer Res 30: 2745-2748.

26. Kuznetsov YuG, Malkin AJ, Land TA, DeYoreo JJ, Barba AP, et al. (1997) Molecular resolution imaging of macromolecular crystals by atomic force microscopy. Biophys J 72: 2357-2364

27. Pechkova E, Sartore M, Giacomelli L, Nicolini C (2007) Atomic force microscopy of protein films and crystals. Rev Sci Instrum 78: 093704.

28. Mollica V, Borassi A, Relini A, Cavalleri O, Bolognesi M, et al. (2001) An atomic force microscopy investigation of protein crystal surface topography. Eur Biophys J 30: 313-318

29. Helliwell JR (1992) Macromolecular Crystallography with Synchrotron Radiation. Cambridge University Press.

30. Pechkova E, Riekel C (2011) Synchrotron radiation and structural proteomics Pan Stanford Series on Nanobiotechnology. Pan Stanford Publishing, Singapore.

31. Chen $\mathrm{H}, \mathrm{He} X$, Sheng $\mathrm{C}, \mathrm{Ma} Y$, Nie H, et al. (2011) Interactions between synchrotron radiation $\mathrm{X}$-ray and biological tissues - theoretical and clinical significance. Int J Physiol Pathophysiol Pharmacol 3: 243-248.

32. Nicolini C, Pechkova E (2006) Structure and growth of ultrasmall protein microcrystals by synchrotron radiation: I. microGISAXS and microdiffraction of P450scc. J Cell Biochem 97: 544-552.

33. Pechkova E, Nicolini C (2006) Structure and growth of ultrasmall protein microcrystals by synchrotron radiation: II. microGISAX and microscopy of lysozyme. J Cell Biochem 97: 553-560.

34. Pechkova E, Nicolini C (2011) In situ study of nanotemplate-induced growth of lysozyme microcrystals by submicrometer GISAXS. J Synchrotron Radiat 18: $287-292$

35. Gebhardt R, Pechkova E, Riekel C, Nicolini C (2010) In situ muGISAXS: I. Experimental setup for submicron study of protein nucleation and growth Biophys J 99: 1256-1261

36. Gebhardt R, Pechkova E, Riekel C, Nicolini C (2010) In situ muGISAXS: II. Thaumatin crystal growth kinetic. Biophys J 99: 1262-1267.

37. Pechkova E, Roth SV, Burghammer M, Fontani D, Riekel C, et al. (2005) microGISAXS and protein nanotemplate crystallization: methods and instrumentation. J Synchrotron Radiat 12: 713-716.

38. Müller-Buschbaum $P$ (2003) Grazing incidence small-angle X-ray scattering: an advanced scattering technique for the investigation of nanostructured polymer films. Anal Bioanal Chem 376: 3-10.

39. Müller Buschbaum P, Gutmann JS, Stamm M, Cubitt R, Cunis S, et al. (2000) Dewetting of thin polymer-blend films examined with GISAXS. Physica B 283: 53-59.

40. Müller-Buschbaum $P$, Roth SV, Burghammer $M$, Diethert $A$, Panagiotou $P$ et al. (2003) Multiple-scaled polymer surfaces investigated with micro-focus grazing incidence small-angle X-ray scattering. Europhysics Lett 61: 639-645.

41. Blanton TN, Huang TC, Toraya H, Hubbard CR, Robie SB, et al. (1995) JCPDS-International Center for Diffraction Data Round Robin Study of silver behenate. A possible low-angle x-ray diffraction calibration standard. Powder Diffraction 10: 91-100.

42. Renaud G, Lazzari R, Leroy F (2009) Probing surface and interface morphology with grazing incidence small angle x-ray scattering. Surf Sci Rep 64: 255-380.

43. Yoneda $Y$ (1963) Anomalous surface reflection of X-rays. Physical Review 161 2010-2013. 
Citation: Nicolini C, Bragazzi NL, Pechkova E, Lazzari R (2014) Ab Initio Semi-Quantitative Analysis of Micro-Beam Grazing-Incidence Small-Angle X-Ray Scattering (M-GISAXS) during Protein Crystal Nucleation and Growth. J Proteomics Bioinform 7: 064-070. doi:10.4172/jpb.1000303

44. CRXO, Laboratory, L. B. N. Center for X-ray Optics.

45. Hammersley AP (1997) FIT2D: An Introduction and Overview. ESRF Internal Report, ESRF97HA02T.

46. Lazzari $R$ (2002) IsGISAXS: a program for grazing-incidence small angle x-ray scattering analysis of supported islands. J Appl Crystallogr 35: 406-421.

47. Lazzari R, Leroy F, Renaud G (2007) Grazing incidence small angle X-ray scattering from dense packing of islands on surfaces: development of DWBA and correlation between particle sizes and spacing. Phys Rev B 76: 125411.

48. Renaud G, Lazzari R, Revenant C, Barbier A, Noblet M, et al. (2003) Real-time monitoring of growing nanoparticles. Science 300: 1416-1419.

49. Renaud G, Ducruet M, Ulrich O, Lazzari R (2004) Apparatus for real time in situ quantitative studies of growing nanoparticles by grazing incidence small angle
$\mathrm{X}$-ray scattering and surface differential reflectance spectroscopy. Nucl Instrum Methods B 222: 667-680.

50. Chaâbane N, Lazzari R, Jupille J, Renaud G, Avellar Soares E (2012) COInduced Scavenging of Supported Pt Nanoclusters: A GISAXS Study. The Journal of Physical Chemistry C 116: 23362-23370.

51. Nicolini C, Bruzzese D, Sivozhelezov V, Pechkova E (2008) Langmuir-Blodgett based lipase nanofilms of unique structure-function relationship. Biosystems 94: 228-232.

52. Guinier A, Fournet G (1955) Small angle scattering of X-rays. John Wiley \& Sons, New York.

53. Riekel C (2000) New avenues in X-ray microbeam experiments. Rep Prog Phys 63: 233-262.
Citation: Nicolini C, Bragazzi NL, Pechkova E, Lazzari R (2014) Ab Initio Semi-Quantitative Analysis of Micro-Beam Grazing-Incidence Small-Angle X-Ray Scattering (M-GISAXS) during Protein Crystal Nucleation and Growth. J Proteomics Bioinform 7: 064-070. doi:10.4172/jpb.1000303
Submit your next manuscript and get advantages of OMICS Group submissions

Unique features:

- User friendly/feasible website-translation of your paper to 50 world's leading languages

Audio Version of published paper

Digital articles to share and explore

Special features:

300 Open Access Journals

25,000 editorial team

21 days rapid review proces

Quality and quick editorial, review and publication processing

Indexing at PubMed (partial), Scopus, EBSCO, Index Copernicus and Google Scholar etc

- Sharing Option: Social Networking Enabled

- Authors, Reviewers and Editors rewarded with online Scientific Credits

- Befter discount for your subsequent articles

Submit your manuscript at: http://www.editorialmanager.com/proteomics 